\title{
Evidence-based medicine
}

\author{
Stephen A Margolis
}

The fact that an opinion has been widely held is no evidence whatever that it is not utterly absurd.

- Bertrand Russell

EVIDENCE-BASED MEDICINE (EBM) hit the headlines around 25 years ago when the McMaster Medical School in Canada named the new learning strategy they had developed. ${ }^{1}$ Since then, EBM has grown from strength to strength. Demonstration of EBM is now a core standard for general practice in Australia, where contemporary practice is based on best available evidence. $^{2}$

Perhaps the most enduring feature of EBM that demonstrates its prowess in guiding modern clinical management is that virtually no one reminisces about the distant, and now extinct, cousins of EBM. The best known of these fundamentally flawed approaches to medicine is 'eminence-based medicine' (EmBM). In this approach, decisions are enforced by the 'elder clinical statesman' using a technique that is a cross between the patronage system and well-meaning descriptions of personal experience extrapolated across a broader field.

Parodies of EmBM abound, including the formation of levels and grades of EmBM promulgated by the Utopian College of Emergency Medicine (UCEM). ${ }^{3}$ Other flawed approaches, as expertly documented by Isaacs and Fitzgerald, ${ }^{4}$ include vehemence-based medicine (stridency of proponent), eloquence-based medicine (sartorial and vocal sophistication of proponent) and nervousness-based medicine (irrational fears of litigation driving irrational management choices).

In a world where we all agree to follow EBM, perhaps the real challenge is when the evidence just is not there. As detailed in The Royal Australian College of General Practitioners' (RACGP's) practice standards, "in the absence of well-conducted clinical trials or other higher order evidence, the opinion of consensus panels of peers is an accepted level of evidence and may be the best available evidence at that time.' ${ }^{2}$ This of course leads to the question: why isn't the evidence available? The solution proposed by the World Organization of Family Doctors (WONCA) conference in 2004 was expanded primary care research and education, to run with a parallel rise in investment in primary care research. ${ }^{5}$

And the outcome since then? There has been significant primary healthcare research capacity building on a broader scale across the globe, including the establishment of multidisciplinary research training programs, resulting in thriving primary healthcare research outputs. ${ }^{6}$ However, as suggested by the current RACGP practice standards, ${ }^{2}$ there is still much work to do.

In this issue of Australian Journal of General Practice, we provide examples illustrating three key pillars of the application of EBM to the general practice clinical environment:

- research focused on primary healthcare

- ongoing education for general practitioners (GPs), to further their understanding of assessing the evidence - EBM used in patient management. Emery, Pirotta, Macrae, et al examine a novel method of risk communication to promote appropriate patient choice of colorectal cancer screening modality. ${ }^{7}$ Parker, Grundy and Bero consider the issue of dissecting research results where there is pharmaceutical industry sponsorship. ${ }^{8}$ Thistlethwaite and Weeks explore GPs' decision making when prescribing new medicines using an EBM approach, ${ }^{9}$ while Spurling, Mitchell and van Driel unlock the mysteries of using Cochrane reviews in clinical decision making. ${ }^{10}$

EBM is now an undisputed cornerstone of clinical practice. Recognition that GPs need general-practice focused, evidence- based answers is spurring on a slow but definitive increase in primary healthcare research. ${ }^{11}$ Our patients are the certain beneficiaries.

\section{Author}

Stephen A Margolis MBBS, MFM, MD, GEM, DRANZCOG, FRACGP, FACRRM, is the Senior Medical Editor of Australian Journal of General Practice; Professor, School of Medicine, Griffith University, Queensland; and Medical Officer with the Royal Flying Doctor Service.

\section{References}

1. Evidence-Based Medicine Working Group. Evidence-based medicine: A new approach to teaching the practice of medicine. JAMA 1992;268(17):2420-25.

2. The Royal Australian College of General Practitioners. Standards for general practices. 5th edn. Melbourne: RACGP, 2017.

3. Life in the Fast Lane. Levels of eminence. Australia: Life in the Fast Lane, 2016. Available at https://lifeinthefastlane.com/the-levels-ofeminence/ [Accessed 3 May 2018].

4. Isaacs D, Fitzgerald D. Seven alternatives to evidence-based medicine. BMJ 1999;319:1618.

5. Rosser WW, van Weel C. Research in family/ general practice is essential for improving health globally. Ann Fam Med 2004;2(Suppl 2):S2-S4.

6. Kidd M, Manning G, Howe A, Qidwai W, Beasley JW, van Weel C. Primary care research. Lancet 2014;384(9955):1671-72.

7. Emery JD, Pirotta M. Macrae F, et al. 'Why don't I need a colonoscopy?': A novel approach to communicating risks and benefits of colorectal cancer screening. Aust J Gen Pract 2018;47(6):343-49.

8. Parker L, Grundy Q, Bero L. Interpreting evidence in general practice: Bias and conflicts of interest. Aust J Gen Pract 2018;47(6):337-40.

9. Thistlethwaite J, Weeks L. Evaluating and prescribing new medicines in general practice. Aust J Gen Pract 2018;47(6):327-31.

10. Spurling G, Mitchell B, van Driel M. Unlocking the value of Cochrane reviews for general practitioners. Aust J Gen Pract 2018;47(6):333-36.

11. Glanville J, Kendrick T, McNally R, Campbell J, Hobbs FDR. Research output on primary care in Australia, Canada, Germany, the Netherlands, the United Kingdom, and the United States: Bibliometric analysis. BMJ 2011;34:d1028. 